\title{
Tolerância de linhagens de arroz de terras altas à seca ${ }^{1}$
}

\author{
Thiago Gledson Rios Terra² ${ }^{2}$ Tarcísio Castro Alves de Barros Leal ${ }^{3}$, \\ Aluízio Borém ${ }^{2}$, Paulo Hideo Nakano Rangel ${ }^{4}$
}

\begin{abstract}
Upland rice tolerance to drought

Water deficiency stress can seriously damage the upland rice crop, mainly reducing its yield. Therefore, the selection of genotypes better adapted to drought is relevant. This study aimed at evaluating agronomic traits and leaf temperature, in $\mathrm{F}_{7}$ upland rice lines under two irrigation conditions (with and without water deficit stress), in order to allow the selection of lines more tolerant to this abiotic stress. In 142 recombinant inbred lines and their two parents, Bico Ganga Curto and Chorinho, the leaf temperature $\left({ }^{\circ} \mathrm{C}\right)$, days to flowering, number of tillers and panicles per linear meter, spikelet sterility $(\%)$, plant height $(\mathrm{cm})$, one thousand spikelets weight $(\mathrm{g})$ and yield $\left(\mathrm{kg} \mathrm{ha}^{-1}\right)$ were evaluated. The experimental design used was a $12 \times 12$ triple lattice, with or without water stress. Fifteen lines were selected by using the Drought Susceptibility Index and compared with their parents by the Tukey test. An increase was observed in the number of days to flowering and spikelet sterility, under water deficit stress. Under the same condition, there was a reduction for plant height and number of tillers and panicles per linear meter. Among all lines, the 51 distinguished itself by presenting a high yield, concerning both environments.
\end{abstract}

KEY-WORDS: Oryza sativa L.; water deficit; Drought Susceptibility Index.

\section{INTRODUÇÃO}

O arroz (Oryza sativa L.) é uma poácea hidrófila que, durante o processo evolutivo, adaptou-se aos mais variados ambientes, com diferentes condições edafoclimáticas. Encontra-se entre os principais cereais consumidos no mundo, principalmente nos países em desenvolvimento, e é cultivado em mais de 148 milhões de hectares, em ecossistemas com temperaturas e regimes hídricos variados.

Aproximadamente $13 \%$ do arroz cultivado encontra-se em ecossistema de terras altas, sem

\section{RESUMO}

O estresse por deficiência hídrica pode acarretar sérios danos à cultura do arroz de terras altas, principalmente na redução da produtividade. Por isto, a seleção de genótipos mais adaptados a esta condição faz-se necessária. Este trabalho avaliou as características agronômicas e temperatura foliar, em linhagens $\mathrm{F}_{7}$ de arroz de terras altas submetidas a duas condições de irrigação (com e sem estresse de deficiência hídrica), no sentido de possibilitar a seleção de materiais mais tolerantes a este estresse abiótico. Em 142 linhagens endogâmicas e seus dois genitores, Bico Ganga Curto e Chorinho, foram avaliados a temperatura foliar $\left({ }^{\circ} \mathrm{C}\right)$, dias até o florescimento, número de perfilhos e de panículas por metro linear, esterilidade das espiguetas (\%), altura da planta $(\mathrm{cm})$, massa de mil espiguetas $(\mathrm{g})$ e produtividade $\left(\mathrm{kg} \mathrm{ha}^{-1}\right)$. $\mathrm{O}$ delineamento experimental utilizado foi o látice triplo $12 \times 12$, com e sem estresse de deficiência hídrica. Foram selecionadas 15 linhagens, por meio do Índice de Susceptibilidade à Seca, as quais foram comparadas com seus genitores, pelo teste Tukey. Verificou-se que houve aumento no número de dias para o florescimento e para a esterilidade das espiguetas, em condições de deficiência hídrica. Nesta mesma condição, houve redução na altura da planta e número de perfilhos e de panículas por metro linear. Dentre as linhagens, destacou-se a 51, que apresentou boa produtividade, em ambas as condições de cultivo.

PALAVRAS-CHAVE: Oryza sativa L.; déficit hídrico; Índice de Susceptibilidade à Seca.

acúmulo de água, sendo influenciado pelo regime hídrico, durante o seu desenvolvimento (Babu et al. 2003). As regiões tropicais apresentam sazonalidade de chuvas, muitas vezes com períodos de excesso e outros com deficiência hídrica, o que pode ocasionar redução na produção. Esta situação tem se intensificado nas últimas décadas, devido ao efeito estufa.

$\mathrm{O}$ estresse por deficiência hídrica provoca diversas alterações bioquímicas, fisiológicas e morfológicas nas plantas, tais como redução na abertura de estômatos, diminuição na absorção de $\mathrm{CO}_{2}$, redução na taxa fotossintética, reflexos negativos sobre

1. Trabalho recebido em dez./2012 e aceito para publicação em jun./2013 (nº registro: PAT 21592).

2. Universidade Federal de Viçosa (UFV), Departamento de Fitotecnia, Viçosa, MG, Brasil. E-mails: tgterra@uft.edu.br, borem@ufv.br. 3. Universidade Federal do Tocantins (UFT), Campus de Gurupi, Gurupi, TO, Brasil.E-mail: tarcisio@uft.edu.br.

4. Embrapa Arroz e Feijão, Santo Antônio de Goiás, GO, Brasil. E-mail: paulo.hideo@embrapa.br. 
o vigor e altura da planta, diminuição na fertilidade do grão de pólen e redução na produtividade (Bota et al. 2004).

Alguns mecanismos morfofisiológicos podem estar relacionados com a tolerância à deficiência hídrica, tais como o uso moderado de água pela planta, habilidade de as raízes explorarem camadas mais profundas do solo, maior relação entre raiz e parte aérea, diminuição no volume das células, aumento na concentração do protoplasto, diminuição no tamanho das folhas, maior espessura e cerosidade da cutícula foliar, ângulo de inclinação da folha, acúmulo de metabólitos e resistência à desidratação das células (Nguyen et al. 1997). O arroz não é uma espécie muito eficiente para evitar a perda de água, porque, dentre outros fatores, possui pouca cera cuticular (Fukai \& Cooper 1995).

A busca por materiais tolerantes à condição de seca, por meio do melhoramento genético, é reconhecida como a estratégia mais eficiente para aliviar a insegurança alimentar causada pela escassez de água (Huang et al. 2007). Todavia, a seleção de genótipos superiores de arroz de terras altas tolerantes à seca pode ser dificultada pela deficiência de informações sobre genótipos nesta condição. Alguns caracteres associados com a tolerância à deficiência hídrica possuem herança quantitativa, sendo fortemente influenciados pelo ambiente de cultivo (Shinozaki \& Yamaguchi-Shinozaki 2007).

O uso do Índice de Susceptibilidade à Seca (ISS) pode ser eficiente na seleção de indivíduos superiores, em condição de estresse por deficiência hídrica, assegurando que os genótipos selecionados possam conter genes para a tolerância à seca (Fischer \& Maurer 1987, Pantuwan et al. 2002, Ouk et al. 2006). A seleção de genótipos pelo uso do ISS pode assegurar certa estabilidade na produção, pois os valores utilizados levam em consideração as produtividades em ambas as condições de cultivo (com e sem deficiência hídrica).

Com isso, o presente trabalho objetivou avaliar características agronômicas e temperatura foliar, em linhagens $\mathrm{F}_{7}$ de arroz de terras altas submetidas a duas condições de irrigação (com e sem estresse por deficiência hídrica), visando à identificação de genótipos tolerantes ao estresse hídrico e de características que possam exercer influência nos mecanismos de tolerância à deficiência hídrica.

\section{MATERIAL E MÉTODOS}

O experimento foi conduzido na Estação Experimental de Pesquisa (EEP) pertencente à Universidade Federal do Tocantins, instalada no Campus Universitário de Gurupi (TO), entre os meses de junho e novembro de 2007. Esta localidade está situada a, aproximadamente, $287 \mathrm{~m}$ de altitude e caracteriza-se, climaticamente, por apresentar temperatura média anual de $26^{\circ} \mathrm{C}$, umidade relativa do ar de $68,5 \%$ e precipitação média anual de $1.400 \mathrm{~mm}$.

Nos meses iniciais de cultivo, não ocorreu precipitação pluvial, mantendo-se o controle sobre a quantidade de água fornecida ao experimento, em ambas as condições de cultivo (Figura 1). Em

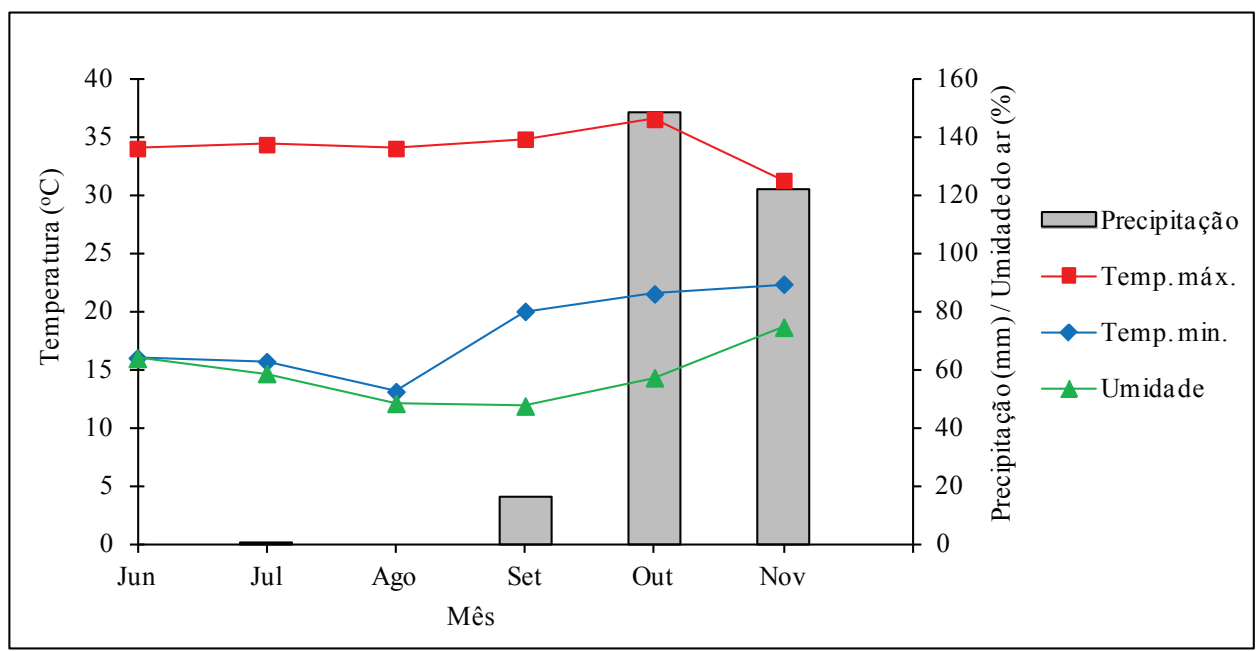

Figura 1. Temperaturas máxima (Temp. máx.) e mínima (Temp. min.) $\left({ }^{\circ} \mathrm{C}\right)$, umidade relativa do ar e precipitação pluvial, de junho a novembro de 2007, em Gurupi (TO). Fonte: Inmet (2008). 
geral, as temperaturas permaneceram relativamente altas, principalmente no final do período, a partir de setembro. Antes da implantação da cultura, o solo do local, classificado como Latossolo Amarelo distrófico com textura arenosa, foi amostrado na camada 0,0-20,0 cm, com o auxílio de um trado, para a caracterização química e granulométrica (Tabela 1).

Foi realizada calagem, por meio da utilização de calcário dolomítico, buscando-se elevar a soma de bases, conforme recomendado por Ribeiro et al. (1999), para a cultura do arroz de terras altas. A semeadura foi realizada no sistema convencional, com duas gradagens pesadas e uma leve. Na adubação de base, aplicou-se $12 \mathrm{~kg} \mathrm{ha}^{-1}, 90 \mathrm{~kg} \mathrm{ha}^{-1}, 48 \mathrm{~kg} \mathrm{ha}^{-1}$ e $20 \mathrm{~kg} \mathrm{ha}^{-1}$ de $\mathrm{N}$ (sulfato de amônio), $\mathrm{P}_{2} \mathrm{O}_{5}$ (super simples), $\mathrm{K}_{2} \mathrm{O}$ (cloreto de potássio) e sulfato de zinco, respectivamente. Por volta dos vinte dias após a semeadura, realizou-se uma adubação de cobertura com $45 \mathrm{~kg} \mathrm{ha}^{-1}$ de $\mathrm{N}$, na forma de ureia.

O controle das plantas daninhas foi realizado em pré-emergência, a partir da aplicação de $0,75 \mathrm{~kg} \mathrm{ha}^{-1}$ do ingrediente ativo (i.a.) do herbicida oxadiazon, utilizando-se pulverizador tratorizado com bico tipo leque. Para o controle da bruzone, realizou-se, aos 75 dias após a semeadura, a aplicação da mistura dos fungicidas Bin (à base de triciclazol 0,3 $\mathrm{kg} \mathrm{ha}^{-1}$ do i.a.) e Stratego (à base de trifloxystrobin + propiconazole $0,05 \mathrm{~kg} \mathrm{ha}^{-1}$ do i.a.), utilizando-se pulverizador costal motorizado.

A lâmina de água foi fornecida sem distinção entre os ambientes (com e sem deficiência hídrica), até os 35 dias após a emergência das plantas de arroz, utilizando-se sistema de irrigação formado por um conjunto autopropelido e carrinho com barras laterais. Nas barras, encontravam-se, na saída dos bicos dissipadores, válvulas reguladoras de pressão, com a finalidade de se ter lâmina de água constante e homogênea, durante a aplicação. Após este período inicial, foi fornecida, para o tratamento com estresse de seca, aproximadamente, a metade da lâmina de água fornecida no tratamento sem estresse. O turno de rega foi ajustado conforme a necessidade da cultura, com o auxílio de tensiômetros localizados na área, cujas cápsulas porosas encontravam-se a $0,15 \mathrm{~m}$ de profundidade, no solo (Stone et al. 1986).

Os tratamentos constaram de 142 linhagens endogâmicas (RIL's) e seus dois genitores, Bico Ganga Curto e Chorinho, ambos Oryza sativa subespécie Japônica, avaliados de acordo com as seguintes características:

a) Temperatura foliar: aos 25 dias após o início do estresse de seca, iniciaram-se as avaliações da temperatura $\left({ }^{\circ} \mathrm{C}\right)$ do dossel foliar, em ambos os ambientes, com duas leituras por parcela, em um total de cinco mensurações. Foram realizadas por meio do termômetro a laser da marca Raytek, tipo Raynger ST, colocado a, aproximadamente, $10 \mathrm{~cm}$ do dossel foliar. Estas eram realizadas antecedendo-se a irrigação, nos horários mais quentes do dia (entre $12 \mathrm{~h} 30$ e 14h00), com a finalidade de se obter dados de temperatura do dossel foliar dos genótipos com o nível mais elevado de tensão de água no solo e de temperatura diária;

b) Florescimento: em cada parcela, considerou-se o florescimento (dias da emergência até o florescimento) a partir do momento em que $50 \%$ das plantas apresentavam flores abertas;

c) Número de perfilhos por metro linear: antecedendo a época da colheita, foi mensurado o número de perfilhos em um metro linear;

d) Número de panículas por metro: foi contado, em um metro linear, o número de panículas, nas plantas de arroz;

e) Espiguetas por panícula: foram coletadas, por amostragem, dez panículas em cada parcela, para a contagem do número de espiguetas férteis e estéreis;

f) Esterilidade das espiguetas: a partir da contagem das espiguetas férteis e estéreis, calculou-se o percentual de esterilidade. Para tanto, utilizou-se a seguinte fórmula: $\mathrm{ES}=(\mathrm{EE} \times 100) \div \mathrm{TE}$, onde $\mathrm{ES}=$ esterilidade das espiguetas, $\mathrm{EE}=$ número de espiguetas estéreis e TE $=$ número total de espiguetas. Os dados de percentagem foram transformados pela fórmula $(\sqrt{ } \mathrm{x})+1$, pois não obedeciam ao modelo de distribuição normal;

Tabela 1. Análise de solo (0,0-20,0 cm) da área experimental (Gurupi, TO, 2007).

\begin{tabular}{|c|c|c|c|c|c|c|c|c|c|c|}
\hline M.O. & $\mathrm{pH}$ & $\mathrm{P}(\mathrm{mel} .)^{(1)}$ & $\mathrm{K}$ & $\mathrm{Ca}$ & $\mathrm{Mg}$ & $\mathrm{Al}$ & $\mathrm{H}+\mathrm{Al}$ & Areia & Silte & Argila \\
\hline$\%$ & $\mathrm{CaCl}_{2}$ & $\mathrm{mg} \mathrm{dm}^{-3}$ & \multicolumn{5}{|c|}{$\mathrm{cmol}_{\mathrm{c}} \mathrm{dm}^{-3}$} & \multicolumn{3}{|c|}{$-\mathrm{g} \mathrm{kg}^{-1}$} \\
\hline 4,75 & 5,5 & 0,3 & 0,097 & 2,36 & 0,38 & 0,25 & 2,3 & 562,5 & 127,5 & 310,0 \\
\hline
\end{tabular}

${ }^{(1)}$ mel. = fósforo extraído pelo método Melich. 
g) Massa de mil espiguetas: para determinação do peso, foram contadas cem espiguetas férteis e pesadas em balança com precisão de $0,002 \mathrm{~g}$;

h) Altura das plantas: foi mensurada a altura de dez plantas por parcela, tomando-se, como base, o solo e o ápice da panícula;

i) Produtividade: a parcela constou de 4 linhas de 3,0 m de comprimento, contudo, a área útil colhida para avaliar a produtividade foram as duas linhas centrais, descartando-se 0,5 m das extremidades.

O delineamento experimental foi o látice triplo $12 \times 12$, sob duas condições de irrigação (com e sem estresse por deficiência hídrica). As parcelas foram compostas por quatro linhas de 3,0 m de comprimento, espaçadas em $0,35 \mathrm{~m}$, com média de 80 sementes por metro linear.

Devido à grande quantidade de genótipos (144) e do volume de dados a serem analisados e, principalmente, apresentados, optou-se por efetuar as análises em parte da população base, selecionando-se materiais com valores médios e extremos. Esta seleção foi feita de acordo com o Índice de Susceptibilidade à Seca (ISS) proposto por Fisher \& Maurer (1978), possibilitando a avaliação e seleção das linhagens $\mathrm{F}_{7}$, evidenciando os caracteres avaliados que estão mais envolvidos com a tolerância à seca, em arroz.

A fórmula utilizada foi: ISS $=[1-($ Yce/Yse $)$ / (1-(Mce/Mse)], sendo Yce = produção do genótipo com estresse, Yse = produção do genótipo sem estresse, Mce $=$ média dos genótipos sob estresse e Mse $=$ média dos genótipos sem estresse. Foram selecionadas 15 linhagens endogâmicas, sendo cinco linhagens mais susceptíveis, cinco intermediárias e cinco mais tolerantes à seca, além dos dois genitores.

Foi realizada a análise de variância dos dados obtidos em cada ambiente (com e sem estresse de seca). Testou-se a homogeneidade das variâncias residuais, para a realização da análise de variância conjunta. As médias dos 17 tratamentos (15 linhagens selecionadas e dois genitores) foram comparadas pelo teste Tukey, a 5\%. Para as análises estatísticas, utilizou-se o software estatístico Genes (Cruz 2006).

\section{RESULTADOS E DISCUSSÃO}

Tomando-se, como base, o ISS (Fisher \& Maurer 1978), foi possível selecionar as linhagens avaliadas neste experimento, buscando-se três grupos distintos de genótipos que apresentassem valores contrastantes para este Índice, agrupando-os em tolerantes, intermediários e susceptíveis à deficiência hídrica, além dos dois genitores da população. Bico Ganga Curto apresentou valores mais elevados que o Chorinho, quanto ao ISS, sugerindo maior tendência à susceptibilidade ao estresse por deficiência hídrica (Tabela 2).

Os cinco genótipos selecionados no grupo dos mais tolerantes à seca apresentaram média de produtividade de $1.616 \mathrm{~kg} \mathrm{ha}^{-1}$, na condição de estresse, enquanto a população total apresentou média de $1.448 \mathrm{~kg} \mathrm{ha}^{-1}$. Talvez o ganho de seleção por meio desse Índice não seja tão significativo, quanto à seleção direta em apenas uma das condições de cultivo, com base na produtividade. No entanto, tende a ocorrer maior estabilidade de produção na população selecionada por meio do ISS, no que se refere à tolerância ao estresse ocasionado por deficiência hídrica.

A partir dos resultados encontrados no atual experimento, pôde-se verificar que houve diferenças significativas $(\mathrm{p}<0,01)$ entre os genótipos, para início da floração e altura da planta. Foi verificada, também, a existência de diferenças significativas $(\mathrm{p}<0,01)$ entre os ambientes de cultivo, para todas as variáveis analisadas, bem como diferenças significativas $(\mathrm{p}<0,01)$ entre os genótipos, para as variáveis floração e altura.

Tabela 2. Genótipos de arroz de terras altas selecionados quanto à tolerância à seca, por meio do ISS (Gurupi, TO, 2007).

\begin{tabular}{|c|c|c|}
\hline Genótipo & Descrição & ISS \\
\hline $\mathrm{T}-1^{(1)}$ & Linhagem 51 & 0,0243 \\
\hline $\mathrm{T}-2$ & Linhagem 130 & 0,0908 \\
\hline $\mathrm{T}-3$ & Linhagem 29 & 0,1257 \\
\hline $\mathrm{T}-4$ & Linhagem 57 & 0,1950 \\
\hline $\mathrm{T}-5$ & Linhagem 19 & 0,1987 \\
\hline G-6 & Chorinho & 0,6310 \\
\hline M-7 & Linhagem 97 & 0,8588 \\
\hline M-8 & Linhagem 38 & 0,8783 \\
\hline M-9 & Linhagem 89 & 0,8811 \\
\hline M-10 & Linhagem 30 & 0,8846 \\
\hline M-11 & Linhagem 48 & 0,8928 \\
\hline G-12 & Bico ganga curto & 1,2622 \\
\hline S-13 & Linhagem 13 & 1,4130 \\
\hline S-14 & Linhagem 24 & 1,4163 \\
\hline S-15 & Linhagem 18 & 1,4209 \\
\hline S-16 & Linhagem 121 & 1,4275 \\
\hline S-17 & Linhagem 144 & 1,4406 \\
\hline
\end{tabular}


Diferenças significativas também foram observadas entre os genótipos, nas avaliações para número de perfilhos e panículas. Houve, ainda, diferenças significativas $(p<0,01)$ entre os ambientes, para todas as variáveis analisadas. Para a produtividade, houve efeito significativo $(\mathrm{p}<0,01)$ na interação Genótipo x Ambiente .

Quando se observa a variável temperatura do dossel foliar, não foram verificadas diferenças significativas entre os genótipos, para ambas as condições avaliadas (Tabela 3). Este resultado corrobora os encontrados por Gomez et al. (2006), que não observaram diferenças $(p>0,05)$, quanto às temperaturas do dossel foliar, entre as cultivares de arroz Bala e Azucena, quando submetidas ao estresse por deficiência hídrica.

As médias de temperatura entre os dois ambientes apresentaram diferenças significativas $(\mathrm{p}<0,05)$, para as linhagens $19,29,48$ e 130. Contudo, existe uma tendência geral de aumento da temperatura, na condição estressada (Tabela 3). Tal fato talvez possa ser explicado devido ao fechamento estomático das plantas nesta condição e, com isto, a transpiração, que é o principal meio de dissipação térmica das plantas, diminui muito, aumentando, assim, a temperatura interna na folha. Maricle et al.
(2007), estudando o efeito da deficiência hídrica e da salinidade em espécies de gramíneas, mostraram que a perda do fluxo de calor diminuiu cerca de $65 \%$, sob condição de diminuição de água no solo, induzindo ao aumento na temperatura da folha de até $4^{\circ} \mathrm{C}$.

Para a variável floração (Tabela 3), não foram verificadas diferenças significativas $(p>0,05)$ entre os genótipos na condição sem estresse, havendo, porém, diferenças $(p<0,05)$ na condição estressada. Dentre os genótipos com menor período de florescimento nesta condição, destaca-se a linhagem 29 e, com maior período de florescimento, as linhagens 89 e 18. Quando se comparam os ambientes, nota-se que houve diferenças para a maioria dos genótipos, com exceção das linhagens 130 e 29, as quais não demonstraram diferenças $(p>0,05)$ entre os ambientes, estando alocadas entre os materiais mais tolerantes, de acordo com o ISS.

Ressalta-se haver tendência de aumento no número de dias para o florescimento, na condição com estresse de seca. Uma possível explicação pode ser o fato de que as plantas, nesta condição, não apresentam, ainda, reservas de fotoassimilados suficientes para o florescimento e posterior enchimento dos grãos. Boonjung \& Fukai (1996) relataram que o estresse de seca, durante o estágio vegetativo em

Tabela 3. Temperatura foliar (TF), dias até o florescimento (FLO), esterilidade das espiguetas (EE), altura (ALT) e massa de 1.000 espiguetas (ME), nos ambientes sem estresse (SE) e com estresse (CE) de seca (Gurupi, TO, 2007).

\begin{tabular}{|c|c|c|c|c|c|c|c|c|c|c|c|}
\hline \multirow{3}{*}{\multicolumn{2}{|c|}{ Genótipos }} & \multirow{2}{*}{\multicolumn{2}{|c|}{$\begin{array}{l}\mathrm{TF} \\
{ }^{\circ} \mathrm{C}\end{array}$}} & \multirow{2}{*}{\multicolumn{2}{|c|}{$\begin{array}{l}\text { FLO } \\
\text { dias }\end{array}$}} & \multirow{2}{*}{\multicolumn{2}{|c|}{$\begin{array}{c}\mathrm{EE}^{(1)} \\
\%\end{array}$}} & \multirow{2}{*}{\multicolumn{2}{|c|}{$\frac{\mathrm{ALT}}{\mathrm{cm}}$}} & \multirow{2}{*}{\multicolumn{2}{|c|}{$\frac{\mathrm{ME}}{\mathrm{g}}$}} \\
\hline & & & & & & & & & & & \\
\hline & & $\mathrm{SE}$ & $\mathrm{CE}$ & SE & $\mathrm{CE}$ & SE & $\mathrm{CE}$ & SE & $\mathrm{CE}$ & SE & $\mathrm{CE}$ \\
\hline Linhagem 51 & $\mathrm{~T} 1^{(2)}$ & $36,6 \mathrm{Aa}$ & $38,8 \mathrm{Aa}$ & $128 \mathrm{Ba}$ & 138 Aabc & $6,75 \mathrm{Aa}$ & 7,37 Aab & $136 \mathrm{Aab}$ & $122 \mathrm{Aab}$ & $26,72 \mathrm{Aa}$ & $24,55 \mathrm{Aa}$ \\
\hline Linhagem 130 & $\mathrm{~T} 2$ & $37,5 \mathrm{Ba}$ & $39,7 \mathrm{Aa}$ & $131 \mathrm{Aa}$ & 139 Aabc & $6,49 \mathrm{Ba}$ & 8,09 Aab & $133 \mathrm{Aab}$ & $129 \mathrm{Aa}$ & $27,36 \mathrm{Aa}$ & $26,14 \mathrm{Aa}$ \\
\hline Linhagem 29 & $\mathrm{~T} 3$ & $36,0 \mathrm{Ba}$ & $39,3 \mathrm{Aa}$ & $121 \mathrm{Aa}$ & $125 \mathrm{Ac}$ & $6,99 \mathrm{Ba}$ & $9,02 \mathrm{Aab}$ & $132 \mathrm{Aab}$ & $109 \mathrm{Bab}$ & $24,76 \mathrm{Aa}$ & $25,40 \mathrm{Aa}$ \\
\hline Linhagem 57 & $\mathrm{~T} 4$ & $37,9 \mathrm{Aa}$ & $38,2 \mathrm{Aa}$ & $123 \mathrm{Ba}$ & $140 \mathrm{Aabc}$ & $6,32 \mathrm{Aa}$ & 7,70 Aab & $142 \mathrm{Aab}$ & $133 \mathrm{Aa}$ & $30,07 \mathrm{Aa}$ & $24,82 \mathrm{Ba}$ \\
\hline Linhagem 19 & T5 & $36,9 \mathrm{Ba}$ & $39,5 \mathrm{Aa}$ & $119 \mathrm{Ba}$ & $131 \mathrm{Abc}$ & $6,97 \mathrm{Aa}$ & 7,98 Aab & $118 \mathrm{Ab}$ & $112 \mathrm{Aab}$ & $26,48 \mathrm{Aa}$ & $26,38 \mathrm{Aa}$ \\
\hline Chorinho & G6 & $37,1 \mathrm{Aa}$ & $37,5 \mathrm{Aa}$ & $121 \mathrm{Ba}$ & $140 \mathrm{Aabc}$ & $6,22 \mathrm{Ba}$ & 8,03 Aab & $131 \mathrm{Aab}$ & $109 \mathrm{Bab}$ & $28,49 \mathrm{Aa}$ & $22,66 \mathrm{Ba}$ \\
\hline Linhagem 97 & I7 & $37,7 \mathrm{Aa}$ & $39,2 \mathrm{Aa}$ & $123 \mathrm{Ba}$ & $135 \mathrm{Aabc}$ & $6,35 \mathrm{Ba}$ & $8,17 \mathrm{Aab}$ & $141 \mathrm{Aab}$ & $125 \mathrm{Bab}$ & $28,58 \mathrm{Aa}$ & $26,25 \mathrm{Aa}$ \\
\hline Linhagem 38 & I8 & $37,1 \mathrm{Aa}$ & $37,9 \mathrm{Aa}$ & $122 \mathrm{Ba}$ & $139 \mathrm{Aabc}$ & 7,59 Aa & 7,89 Aab & $148 \mathrm{Aa}$ & $129 \mathrm{Ba}$ & $23,56 \mathrm{Aa}$ & $23,32 \mathrm{Aa}$ \\
\hline Linhagem 89 & I9 & $37,2 \mathrm{Aa}$ & $37,9 \mathrm{Aa}$ & $133 \mathrm{Ba}$ & $147 \mathrm{Aa}$ & $5,87 \mathrm{Ba}$ & 8,09 Aab & $144 \mathrm{Aab}$ & $135 \mathrm{Aa}$ & $26,85 \mathrm{Aa}$ & $27,34 \mathrm{Aa}$ \\
\hline Linhagem 30 & $\mathrm{I} 10$ & $36,2 \mathrm{Aa}$ & $37,9 \mathrm{Aa}$ & $122 \mathrm{Ba}$ & $143 \mathrm{Aab}$ & $5,64 \mathrm{Ba}$ & $8,12 \mathrm{Aab}$ & $133 \mathrm{Aab}$ & $127 \mathrm{Aa}$ & $26,34 \mathrm{Aa}$ & $24,35 \mathrm{Aa}$ \\
\hline Linhagem 48 & I11 & $36,6 \mathrm{Ba}$ & $39,2 \mathrm{Aa}$ & $127 \mathrm{Ba}$ & $140 \mathrm{Aab}$ & $5,63 \mathrm{Aa}$ & $6,45 \mathrm{Ab}$ & $133 \mathrm{Aab}$ & $127 \mathrm{Aa}$ & $28,97 \mathrm{Aa}$ & $25,63 \mathrm{Aa}$ \\
\hline Bico ganga curto & G12 & $37,1 \mathrm{Aa}$ & $37,4 \mathrm{Aa}$ & $131 \mathrm{Ba}$ & $142 \mathrm{Aab}$ & $5,69 \mathrm{Ba}$ & 7,80 Aab & $131 \mathrm{Aab}$ & $127 \mathrm{Aa}$ & $26,14 \mathrm{Aa}$ & $26,00 \mathrm{Aa}$ \\
\hline Linhagem 13 & $\mathrm{~S} 13$ & $37,9 \mathrm{Aa}$ & $38,5 \mathrm{Aa}$ & $122 \mathrm{Ba}$ & 139 Aabc & $6,19 \mathrm{Ba}$ & 8,79 Aab & $141 \mathrm{Aab}$ & $116 \mathrm{Bab}$ & $30,05 \mathrm{Aa}$ & $23,56 \mathrm{Ba}$ \\
\hline Linhagem 24 & S14 & $38,0 \mathrm{Aa}$ & $38,7 \mathrm{Aa}$ & $127 \mathrm{Ba}$ & $140 \mathrm{Aabc}$ & 7,03 Ba & $9,22 \mathrm{Aa}$ & $138 \mathrm{Aab}$ & $121 \mathrm{Bab}$ & $27,91 \mathrm{Aa}$ & $24,32 \mathrm{Aa}$ \\
\hline Linhagem 18 & S15 & $39,0 \mathrm{Aa}$ & $38,6 \mathrm{Aa}$ & $128 \mathrm{Ba}$ & $146 \mathrm{Aa}$ & $6,94 \mathrm{Aa}$ & 7,95 Aab & $126 \mathrm{Aab}$ & $98 \mathrm{Bb}$ & $25,41 \mathrm{Aa}$ & $23,56 \mathrm{Aa}$ \\
\hline Linhagem 121 & $\mathrm{~S} 16$ & $37,2 \mathrm{Aa}$ & $37,3 \mathrm{Aa}$ & $128 \mathrm{Ba}$ & $144 \mathrm{Aab}$ & $5,30 \mathrm{Ba}$ & 8,04 Aab & $141 \mathrm{Aab}$ & $126 \mathrm{Aab}$ & $28,79 \mathrm{Aa}$ & $24,88 \mathrm{Aa}$ \\
\hline Linhagem 144 & $\mathrm{~S} 17$ & $37,6 \mathrm{Aa}$ & $37,3 \mathrm{Aa}$ & $128 \mathrm{Ba}$ & $145 \mathrm{Aab}$ & $5,53 \mathrm{Ba}$ & 7,90 Aab & $137 \mathrm{Aab}$ & $115 \mathrm{Bab}$ & $28,88 \mathrm{Aa}$ & $25,74 \mathrm{Aa}$ \\
\hline
\end{tabular}


arroz, alongou este período e atrasou, também, a maturidade fisiológica dos grãos. Heinemann \& Stone (2009), em trabalho realizado com quatro variedades de arroz de terras altas sob condição de estresse por deficiência hídrica, mostraram que, sob esta condição, o período de florescimento aumentou em até 11 dias e a maturação fisiológica em até 18 dias.

A esterilidade das espiguetas é uma característica muito influenciada pela condição de estresse de seca e depende da capacidade de a planta produzir e translocar fotoassimilados para o enchimento dos grãos, mesmo sob tal condição (Jongdee et al. 2006). Contudo, nota-se que, na condição sem estresse, não houve diferenças significativas $(p>0,05)$ entre os genótipos (Tabela 3). Jagadish et al. (2007) relataram que a esterilidade das espiguetas pode estar relacionada com a temperatura diurna elevada, o que inviabiliza o grão de pólen.

Plantas submetidas a estresse de seca, em geral, apresentam redução na taxa fotossintética e reflexos negativos na produção de biomassa e, consequentemente, na altura. Para a maioria dos genótipos em questão, principalmente aqueles que estão alocados dentre os mais susceptíveis, foram verificadas diferenças $(\mathrm{p}<0,05)$ entre os ambientes de cultivo, para a altura das plantas (Tabela 3). Os dados corroboram aqueles encontrados por Bernier et al. (2007), que avaliaram linhagens provenientes do cruzamento de uma variedade susceptível ao estresse hídrico (Way Rarem, subespécie índica) com outra tolerante (Vandana, subespécie japônica), sob estresse ocasionado por deficiência hídrica.

$\mathrm{O}$ peso de grãos foi uma característica que não apresentou diferenças significativas $(p>0,05)$ entre os genótipos, para ambas as condições de cultivo. Não houve, também, diferenças significativas $(p>0,05)$ entre os ambientes, para esta característica, com exceção do genitor Chorinho e da linhagem 24, que apresentaram redução na condição de estresse de seca (Tabela 3). Existe, porém, uma tendência de redução no peso dos grãos, quando submetidos a este estresse.

A produtividade, em geral, apresentou diferenças entre os genótipos e, principalmente, redução na condição estressada (Jongdee et al. 2006, Venuprasad et al. 2007). Destacou-se, dentre os genótipos, a linhagem 51, que se apresentou entre as melhores, em ambas as condições de cultivo, e também não apresentou diferença significativa $(p<0,05)$ entre os ambientes de cultivo (Tabela 4).

Os demais genótipos do grupo tolerante não se enquadraram como os mais produtivos, na condição sem estresse de seca, e apresentaram redução na produtividade, no ambiente estressado. Kumar et al.

Tabela 4. Produtividade (PROD), número de espiguetas por panícula (EP), número de perfilhos (PER) e de panículas por metro linear (PAN) de dezessete genótipos de arroz, nos ambientes sem estresse (SE) e com estresse (CE) de seca (Gurupi, TO, 2007).

\begin{tabular}{|c|c|c|c|c|c|c|c|c|c|}
\hline \multirow{2}{*}{\multicolumn{2}{|c|}{ Genótipos }} & \multicolumn{2}{|c|}{ PRO $\left(\mathrm{kg} \mathrm{ha}^{-1}\right)$} & \multicolumn{2}{|c|}{ EP } & \multicolumn{2}{|c|}{ PER } & \multicolumn{2}{|c|}{ PAN } \\
\hline & & SE & $\mathrm{CE}$ & SE & $\mathrm{CE}$ & $\mathrm{SE}$ & $\mathrm{CE}$ & $\mathrm{SE}$ & $\mathrm{CE}$ \\
\hline Linhagem 51 & $\mathrm{~T} 1^{(1)}$ & $2.534 \mathrm{Aabc}$ & $2.529 \mathrm{Aa}$ & $108,7 \mathrm{Aa}$ & $110 \mathrm{Aa}$ & $80 \mathrm{Aa}$ & $51 \mathrm{Ba}$ & $60 \mathrm{Aa}$ & $36 \mathrm{Ba}$ \\
\hline Linhagem 130 & $\mathrm{~T} 2$ & $1.443 \mathrm{Ac}$ & $1.219 \mathrm{Aa}$ & $124,2 \mathrm{Aa}$ & $118 \mathrm{Aa}$ & $75,33 \mathrm{Aa}$ & $48,7 \mathrm{Ba}$ & $53 \mathrm{Aa}$ & $35 \mathrm{Aa}$ \\
\hline Linhagem 29 & T3 & $1.676 \mathrm{Abc}$ & $1.490 \mathrm{Aa}$ & $128,6 \mathrm{Aa}$ & $100 \mathrm{Ba}$ & $95,33 \mathrm{Aa}$ & $63,3 \mathrm{Ba}$ & $71 \mathrm{Aa}$ & $43 \mathrm{Ba}$ \\
\hline Linhagem 57 & $\mathrm{~T} 4$ & $1.705 \mathrm{Abc}$ & $1.476 \mathrm{Aa}$ & $133,8 \mathrm{Aa}$ & $102 \mathrm{Ba}$ & $102,7 \mathrm{Aa}$ & $64,3 \mathrm{Ba}$ & $82 \mathrm{Aa}$ & $50 \mathrm{Ba}$ \\
\hline Linhagem 19 & $\mathrm{~T} 5$ & $1.586 \mathrm{Ac}$ & $1.371 \mathrm{Aa}$ & $110,0 \mathrm{Aa}$ & $104 \mathrm{Aa}$ & $73,67 \mathrm{Aa}$ & $51,7 \mathrm{Ba}$ & $60 \mathrm{Aa}$ & $37 \mathrm{Aa}$ \\
\hline Chorinho & G6 & 2.614 Aabc & $1.747 \mathrm{Aa}$ & $150,5 \mathrm{Aa}$ & $106 \mathrm{Ba}$ & $86,33 \mathrm{Aa}$ & $39,3 \mathrm{Ba}$ & $70 \mathrm{Aa}$ & $31 \mathrm{Ba}$ \\
\hline Linhagem 97 & $\mathrm{I} 7$ & 2.481 Aabc & $1.376 \mathrm{Aa}$ & $105,8 \mathrm{Aa}$ & $99,3 \mathrm{Aa}$ & $98,33 \mathrm{Aa}$ & $46 \mathrm{Ba}$ & $79 \mathrm{Aa}$ & $32 \mathrm{Ba}$ \\
\hline Linhagem 38 & I8 & 3.457 Aabc & $1.841 \mathrm{Ba}$ & $143,2 \mathrm{Aa}$ & $102 \mathrm{Ba}$ & $96 \mathrm{Aa}$ & $51,3 \mathrm{Ba}$ & $73 \mathrm{Aa}$ & $41 \mathrm{Ba}$ \\
\hline Linhagem 89 & I9 & $2.114 \mathrm{Aabc}$ & $1.167 \mathrm{Aa}$ & $137,2 \mathrm{Aa}$ & $96,9 \mathrm{Ba}$ & $61,33 \mathrm{Aa}$ & $34,7 \mathrm{Ba}$ & $53 \mathrm{Aa}$ & $39 \mathrm{Aa}$ \\
\hline Linhagem 30 & $\mathrm{I} 10$ & 2.843 Aabc & $1.434 \mathrm{Ba}$ & $128,6 \mathrm{Aa}$ & $92,7 \mathrm{Ba}$ & $96 \mathrm{Aa}$ & $51,7 \mathrm{Ba}$ & $78 \mathrm{Aa}$ & $39 \mathrm{Ba}$ \\
\hline Linhagem 48 & I11 & $3.933 \mathrm{Aab}$ & $2.157 \mathrm{Ba}$ & $129,2 \mathrm{Aa}$ & $110 \mathrm{Aa}$ & $84 \mathrm{Aa}$ & $32,7 \mathrm{Ba}$ & $70 \mathrm{Aa}$ & $23 \mathrm{Ba}$ \\
\hline Bico ganga curto & G12 & $4.167 \mathrm{Aa}$ & $1.409 \mathrm{Ba}$ & $134,5 \mathrm{Aa}$ & $123 \mathrm{Aa}$ & $90,33 \mathrm{Aa}$ & $41,3 \mathrm{Ba}$ & $70 \mathrm{Aa}$ & $30 \mathrm{Ba}$ \\
\hline Linhagem 13 & S13 & 3.434 Aabc & $872 \mathrm{Ba}$ & $148,1 \mathrm{Aa}$ & $102 \mathrm{Ba}$ & $96 \mathrm{Aa}$ & $62,7 \mathrm{Ba}$ & $77 \mathrm{Aa}$ & $51 \mathrm{Ba}$ \\
\hline Linhagem 24 & S14 & $4.367 \mathrm{Aa}$ & $1.286 \mathrm{Ba}$ & $138,8 \mathrm{Aa}$ & $117 \mathrm{Aa}$ & $93,33 \mathrm{Aa}$ & $54 \mathrm{Ba}$ & $69 \mathrm{Aa}$ & $46 \mathrm{Aa}$ \\
\hline Linhagem 18 & S15 & 3.014 Aabc & $938 \mathrm{Ba}$ & $133,4 \mathrm{Aa}$ & $102 \mathrm{Ba}$ & $83 \mathrm{Aa}$ & $38 \mathrm{Ba}$ & $66 \mathrm{Aa}$ & $28 \mathrm{Ba}$ \\
\hline Linhagem 121 & S16 & $4.000 \mathrm{Aa}$ & $1.114 \mathrm{Ba}$ & $153,4 \mathrm{Aa}$ & $118 \mathrm{Ba}$ & $84,33 \mathrm{Aa}$ & $42,7 \mathrm{Ba}$ & $63 \mathrm{Aa}$ & $30 \mathrm{Ba}$ \\
\hline Linhagem 144 & S17 & $4.324 \mathrm{Aa}$ & $1.191 \mathrm{Ba}$ & $144,3 \mathrm{Aa}$ & $96,2 \mathrm{Ba}$ & $93 \mathrm{Aa}$ & $50 \mathrm{Ba}$ & $68 \mathrm{Aa}$ & $37 \mathrm{Ba}$ \\
\hline
\end{tabular}


(2008) observaram redução de 100\% na produtividade, em genótipos de arroz mais susceptíveis ao estresse de seca. Bernier et al. (2007), estudando o efeito do estresse ocasionado pela deficiência hídrica, em linhagens de arroz oriundas do cruzamento de duas variedades de terras altas, uma índica considerada susceptível (Way Rarem) e outra japônica considerada tolerante (Vandana) a tal condição, encontraram variação na produção entre as linhagens e redução de $88 \%$, na média, sob a condição de estresse hídrico.

O número de espiguetas por panícula (Tabela 4) não variou entre os genótipos avaliados para as duas condições de cultivo. Este resultado pode ser explicado pelo fato de os genitores não apresentarem diferença para esta característica, não tendo apresentado, assim, diferenças $(p>0,05)$ entre as linhagens. Houve, porém, redução na condição estressada, para a maioria dos genótipos, principalmente os do grupo dos susceptíveis.

O número de perfilhos e de panículas por metro linear não apresentaram diferenças significativas $(p>0,05)$ entre os genótipos, para as duas condições de cultivo. Diferenças foram encontradas $(p<0,05)$ entre os ambientes, para as duas variáveis em questão, tendendo à redução, na condição estressada (Tabela 4). O arroz reage ao estresse causado por deficiência hídrica, apresentando reduções na altura das plantas, área foliar, produção de biomassa, aborto de perfilhos e no atraso do desenvolvimento reprodutivo (Guimarães et al. 2011).

\section{CONCLUSÕES}

1. O estresse de seca contribuiu para a redução na altura da planta, número de perfilhos e de panículas e produtividade, e para o aumento da época de florescimento e esterilidade das espiguetas.

2. A temperatura do dossel foliar não apresentou diferenças significativas entre os genótipos, em nenhuma das condições avaliadas.

3. Dentre as linhagens estudadas, destacou-se a 51, por apresentar boa produtividade, em ambas as condições de cultivo.

\section{REFERÊNCIAS}

BABU, R. C. et al. Genetic analysis of drought resistance in rice by molecular markers: association between secondary traits and field performance. Crop Science, Madison, v. 43, n. 4, p. 1457-1469, 2003.
BERNIER, J. et al. A large-effect QTL for grain yield under reproductive-stage drought stress in upland rice. Crop Science, Madison, v. 47, n. 2, p. 507-518, 2007.

BOONJUNG, H.; FUKAI, S. Effects of soil water deficit at different growth stages on rice growth and yield under upland conditions: 2. Phenology, biomass production and yield. Field Crops Research, New York, v. 48, n. 1, p. 47-55, 1996.

BOTA, J.; MEDRANO, H.; FLEXAS, J. Is photosynthesis limited by decreased Rubisco activity and RuBP content under progressive water stress? New Phytologist, Nancy, v. 162, n. 3, p. 671-681, 2004.

CRUZ, C. D. Programa Genes: biometria. Viçosa: UFV, 2006.

FISHER, R. A.; MAURER, R. Drought resistance in spring wheat cultivars: I. Grain yield responses. Australian Journal of Agricultural Research, Collingwood, v. 29, n. 5, p. 897-912, 1978.

FUKAI S.; COOPER, M. Development of droughtresistant cultivars using physio-morphological traits in rice. Field Crops Research, New York, v. 40, n. 1, p. $67-$ 86, 1995.

GOMEZ, S. M. et al. Mapping QTLs linked to physiomorphological and plant production traits under drought stress in rice (Oryza sativa L.) in the target environment. American Journal of Biochemistry and Biotechnology, New York, v. 2, n. 4, p. 161-169, 2006.

GUIMARÃES, C. M. et al. Sistema radicular do arroz de terras altas sob deficiência hídrica. Pesquisa Agropecuária Tropical, Goiânia, v. 41, n. 1, p. 126-134, 2011.

HEINEMANN, A. B.; STONE, L. F. Efeito da deficiência hídrica no desenvolvimento e rendimento de quatro cultivares de arroz de terras altas. Pesquisa Agropecuária Tropical, Goiânia, v. 39, n. 2, p. 134-139, 2009.

HUANG, Y.; XIAO, B.; XIONG, L. Characterization of a stress responsive proteinase inhibitor gene with positive effect in improving drought resistance in rice. Planta, Berkeley, v. 226, n. 1, p. 73-85, 2007.

INSTITUTO NACIONAL DE METEOROLOGIA (Inmet). Monitoramento das estações automáticas: Gurupi - TO. 2008. Disponível em: <http://www.inmet. gov.br/sonabra/maps/automaticas.php>. Acesso em: 15 jul. 2008.

JAGADISH, S. V. K.; CRAUFURD, P. Q.; WHEELER, T. R. High temperature stress and spikelet fertility in rice (Oryza sativa L.). Journal of Experimental Botany, Lancaster, v. 58, n. 7, p. 1627-1635, 2007.

JONGDEE, B. et al. Improving drought tolerance in rainfed lowland rice: an example from Thailand. 
Agricultural Water Management, Brisbane, v. 80, n. 3, p. 225-240, 2006.

KUMAR, A. et al. Breeding for drought tolerance: direct selection for yield, response to selection and use of drought-tolerant donors in upland and lowland-adapted populations. Field Crops Research, New York, v. 107, n. 3, p. 221-231, 2008.

MARICLE, B. R.; COBOS, D. R.; CAMPBELL, C. S. Biophysical and morphological leaf adaptations to drought and salinity in salt marsh grasses. Environmental and Experimental Botany, Paris, v. 60, n. 3, p. 458-467, 2007.

NGUYEN, H. T.; BABU, R. C.; BLUM, A. Breeding for drought resistance in rice: physiology and molecular genetics considerations. Crop Science, Madison, v. 37, n. 5, p. 1426-1437, 1997.

OUK, M. et al. Use of drought response index for identification of drought tolerant genotypes in rainfed lowland rice. Field Crops Research, New York, v. 99, n. 1, p. 48-58, 2006.
PANTUWAN, G. et al. Yield response of rice (Oryza sativa L.) genotypes to drought under rainfed lowlands: Part 1. Grain yield and yield components. Field Crops Research, New York, v. 73, n. 1, p. 153-168, 2002.

RIBEIRO, A. C.; GUIMARÃES, P. T. G.; ALVAREZ, V. H. Recomendações para o uso de corretivos e fertilizantes em Minas Gerais: $5^{a}$ aproximação. Viçosa: SBCS, 1999.

SHINOZAKI, K.; YAMAGUCHI-SHINOZAKI, K. Gene networks involved in drought stress response and tolerance. Journal of Experimental Botany, Lancaster, v. 58, n. 1, p. 221-227, 2007.

STONE, L. F.; MOREIRA, J. A. A.; SILVA, S. C. da. Tensão da água no solo e produtividade do arroz. Santo Antônio de Goiás: Embrapa-CNPAF, 1986. (Circular técnica, 19).

VENUPRASAD, R.; LAFITTE, H. R.; ATLIN, G. N. Response to direct selection for grain yield under drought stress in rice. Crop Science, Madison, v. 47, n. 1, p. $285-$ 293, 2007. 